4th International Scientific Conference SEC-IASR 2019, Galati, Romania, 7th - 8th June, 2019

\title{
Methodological Aspects Concerning the Psychoeducational Intervention in the Case of Emotional and Behavioral Disorders of Children with Migrant Parents
}

\author{
Sandrina MINDU \\ https://doi.org/10.18662/lumproc/sec-iasr2019/24
}

How to cite: Mindu, S. (2020). Methodological Aspects Concerning the Psychoeducational Intervention in the Case of Emotional and Behavioral Disorders of Children with Migrant Parents. In S. Marin \& P. Moisescu (vol. eds.), Lumen Proceedings: Vol. 12. 4th International Scientific Conference SEC-IASR 2019 (pp. 227-239). Iasi, Romania: LUMEN Publishing House.

https://doi.org/10.18662/lumproc/sec-iasr2019/24 



\title{
Methodological Aspects Concerning the Psychoeducational Intervention in the Case of Emotional and Behavioral Disorders of Children with Migrant Parents
}

\author{
Sandrina MINDU ${ }^{1}$
}

\begin{abstract}
The dynamics of family structure modifications in Romania is quite intense, on the background of economic, political, moral instability which manifests at national level. The number of families where the parents are separated from the children because they left the country for work and where the role of the parents is filled by the extended family members (grandparents, aunts, uncles or other relatives) is larger from year to year. Under these circumstances, the family is challenged to identify new resources and find new strategies so as to maintain each member's relational balance and emotional health. The present research aims as a general objective to bighlight a possible methodological structure for psychoeducational intervention in the case of emotional and behavioral disorders of children whose parents left to work in European countries. The practical-applicative objective is to identify the ways in which, within the psychoeducational intervention program, the resilience of children and parents can be increased in the context of family structure modification. Integrating the family into a psychoeducational approach focused on increasing the resilience of its members to separation, developing socio-emotional skills, flexibility and autonomy may be a solution to minimize the negative effects on the psychological development of children that might occur in this context of family structure modification.
\end{abstract}

Keywords: assisted resilience; socio-emotional skills; experiential approach; migrant parents. 


\section{Introduction}

Labor migration from Romania to other countries in the European Union is a phenomenon that has increased in recent years due to economic instability, labor market conditions, economic recession and insecurity in the social space. In this context, the family is the group most affected because the separation deteriorates the system of intra-familial relations, it creates misunderstandings and tensions between its members, it changes the way roles are exercised and, most of all, it interrupts the natural flow of the relationship between parent and child.

In a study on the redistribution of roles in migrant families, Lupu A. states that the family, faced with the phenomenon of migration, undergoes structural changes and experiences difficulties because they must ensure that the same set of needs are met, but in a fundamentally modified context. The departure of a family member to a foreign country for work produces an imbalance of the family system in the way roles are exercised, and the dysfunction must be solved by a redistribution of the specific tasks. If the departure of a family member brings a gain in the satisfaction of primary needs (food, clothing, better living conditions, etc.) there is the possibility of a loss in the area of satisfying the affective needs, and, in this case, the most affected members of the family system are the children [4].

Studies concerning the impact of parental migration on children show that the latter face strong negative emotions such as fear of abandonment, sadness, confusion, helplessness, anger, irascibility, which result, over time, in behavioral disorders such as aggression, lying, school absenteeism, oppositional behavior.

Yanovich L. emphasizes that the adverse effects of parental migration on the children left behind are reflected in the deterioration of academic performance, lack of motivation for learning, the occurrence of juvenile delinquency, health problems and drug use. According to another study, the stability of the family and its future development are also in danger, with divorce being frequent among migrants. The remaining children are vulnerable to human trafficking and labor exploitation [12].

The same aspect is highlighted by Botezat A. and Pfeiffer F. who show that parental migration is linked to serious health problems of the children remaining in the country and a higher probability that they will develop a depressive disorder, the effect being greater for children in the rural areas [2]. In the same context, by analyzing the effects caused by deprivation of parental affection, Toth G. underlines the most important direct consequence of the parents' migration, namely depriving the child of parental affection and of the supervision necessary for the latter's normal 
development. Depending on the parents' departure for longer periods and the child's stay in the care of people who do not have the capacity and/ or competence to provide them with emotional and educational support, negative effects may occur in terms of their health and mental development, involvement in school activities and their results, engaging in deviant or ageinappropriate behaviors and being subjected to exploitation or other types of abuse [11].

\section{Problem Statement}

In this context, of the negative effects of the parents' migration, the question arises of re-establishing the relationship between parents who "leave their children" and children who are "left by parents". This aspect requires accepting this reality and the involvement of the family, community and school in identifying and implementing strategies to minimize the emotional "costs" of this life situation. The multitude of possibilities for approaching life in the context of contemporary challenges requires a paradigm shift for those involved in the education of children with migrant parents, the opening of mental boundaries to new ways of looking at the relationship between parents and children, educators and educated, extended family and children. Thus, it proves the usefulness of psychoeducating the families where there are migrant parents so as to orient them towards the real resources they have and, implicitly, the exit from victimization.

In order to achieve this, one must understand the psychological aspects of children's development, the four categories of their needs: the need for love and security, the need for new experiences, for stimulation, the need to be praised and acknowledged as capable, the need for responsibilities, their dynamics during the child's evolution as well as the emotional implications of the separation process [10]. Badea M. notes that any experience of separation, regardless of its form, the moment, the age, the stage in which it takes place, generates an internal alert state, which mobilizes the action of seeking and restoring contact. Separation is frustrating and that is why one cannot stay in this state for too long without experiencing fear, worry, panic, despair, longing, regret, helplessness. Tolerance to the frustration generated by separation varies from person to person, from one age and stage to another. Any experience of separation leads almost instinctively to the search for other actions of relief, reassurance and assurance [1].

In this context, one can speak of psychoeducation in the sense that managing the experience of separation means developing the inner 
mechanism of self-containment for these emotions so that the child and the adult are aware of them, but do not feel dominated and overwhelmed by their presence. This is a process that needs to be undergone while being aware that the experience of separation is a part of existence, since it can occur in many situations and throughout life. It is a constant reality of our relationships and choices, despite the fact that its general perception is debatable [1].

Boza M., speaking about distance parenting, states that, during the economic reforms, new family configurations have emerged, such as the "transnational family", as a result of the massive exodus of people who left to earn a living abroad, hence the question: "how is parental care reconfigured across borders within the transnational family space?" It is acknowledged that transnational, multi-local families are becoming more frequent and, therefore, transnational parenting is a widespread phenomenon in the world that needs to be looked at more closely.

In other words, being a reality of the Romanian society, involving major and multiple changes in a family, the migration of parents needs to be taken seriously by the community, by the specialists involved in the educational reform, by the educators and, implicitly, by the family itself. In the theory of ambiguous loss, Boss, quoted by Boza, suggested that, in this case, stress is caused by change or by the threat of change affecting the structure, roles and tasks within the family system. The stress of ambiguous loss persists, as there is no closure [3]. It is as if the children remain "suspended", they do not understand what is happening to them, they are separated from their parents without actually being separated. Living this emotion on a subjective level is very profound at the age of early and middle childhood.

If we were to analyze the reactions of children to separation from the perspective of attachment theory, we would reach the conclusion that, mirroring manifestations of deficient attachments, the following types of behavior can be outlined in the case of children separated from parents: internalization, chronic anxiety, poor eye contact, aggressive behavior, indiscriminate attachment, overcompetence, lack of self-awareness or delay in developing self-awareness, difficulties of control, the " 2 or 20 " syndrome (characteristic of children with attachment deficiencies, who sometimes seem too old for their age, and other times immature, who seem to dislike showing their true age and who can resist the restrictions imposed on their behavior; they can behave as 20 -year-olds, but when limits are set, they resort to hysteric episodes specific to 2-year-olds) [8].

Taken together, attachment theory and the theory of ambiguous loss can provide a perspective for understanding the effects on children of family 
separation and reunification as a result of migration. Families with migrant parents also have to cope with the separation and reunification, as the periodic return of parents at home can be confusing for both the child and the parents. Hence, the importance of the correct management of this situation by the adults involved in the growth and development of the child.

For the adaptive integration of separation by the family with changes in structure and so as to prevent the occurrence of emotional and/ or behavioral disorders in the case of children, the terms resilience and assisted resilience are brought to the attention of the specialists in psychoeducation (when aiming to implement intervention programs). Grotberg E., quoted by Mitrofan N., defines resilience as the universal ability that enables a person, group or community to prevent, minimize or overcome the harmful effects of adversity [9]. Theoretically, resilience characterizes a person who has experienced or is experiencing a traumatic event or chronic adversity and who shows good adaptability (which has different meanings depending on age and socio-cultural context).

Resilience is the result of an interactive process among the person, family and the environment [7]. Under these conditions, not only the individual, but also the families have the potential to adapt, mend and evolve through assisted resilience programs focused on strengthening the adaptive functioning of the family in conditions of adversity [5].

Resilience-focused intervention (assisted resilience programs) is inspired by what has been called a "strengths-based intervention". Specialists working from the point of view of assisted resilience should highlight and develop the potential of people at risk. Thus, the emphasis is placed on a number of individual characteristics known as protective factors and facilitators of resilience: self-esteem, assertiveness, ability to arouse sympathy, positive self-image, sense of control over life, creativity, humor.

At the same time, the specialists must discover the resources existing in the entourage of the person; primarily, adults who can maintain, over a long period of time, meaningful and empathetic relationships with the person. Another important entourage resource is represented by the support networks (friends, colleagues) that contribute to the creation of a secure and welcoming environment, a true "protection net" around the person. The role of the specialist is to discover and evaluate these resources, to orient the person towards these resources, to contribute to the creation of such networks when they are absent. When using intervention methods such as assisted resilience, three precautionary measures must be taken:

the intervention should not be focused solely on the individual (since resilience is the product of interactions, it is necessary to involve the family and the environment); 
not to easily overlook the suffering, focusing the intervention on the competences and strengths of the person;

not to stigmatize people at risk by applying interventions oriented only on them [7](the intervention must target the school group to which the child belongs).

\section{Research Questions/Aims of the research}

The psychoeducation of families in whose life scenario there are structural changes due to the migration of one or both parents is achieved through the school-family-community partnership, through multidisciplinary teams made up of educational counselor, psychological counselor, social worker, pediatric neuropsychiatrist, primary school and/ or preschool teacher. Moreover, the effective participation of the members of the nuclear and extended family in the process of improving/ remitting the symptomatology of the emotional and/ or behavioral disorder of the child affected by the separation from his parents facilitates the integration of the problematic, conflictogenic situation arisen in the family life, through healthy coping mechanisms. The family thus becomes responsible for their own "recovery", for overcoming the dysfunctionality.

The general objective of the present study is to provide a possible methodological picture for the psychological intervention in case of emotional and behavioral disorders of the children whose parents left to work in other countries.

The practical-applicative objective consists in identifying the ways in which, within an integrative psychoeducational program, the resilience of children and parents can be increased in the context of temporarily modifying the family structure.

In the process of elaborating and implementing the psychoeducational program, the psychotherapeutic objectives of the intervention on the child were:

1. Identification of strategies of adjustment to the traumatic situation developed by the child (compensatory behaviors: overadaptativebehaviors; disturbing behaviors);

2. Remitting / improving the symptoms of the emotional and / or behavioral disorder;

3. Increasing resilience (emotional identification, expression and self-regulation, facilitating understanding, acceptance and reintegration of rejected or self-blocking parts of self, improving perception of oneself 
and one's family, identifying and using one's own resources, developing independence, self-efficiency, relational skills).

Psychotherapeutic objectives of the intervention on the family were materialized in:

1. Identification, expression and self-regulation of the emotions and cognitions about self by the migrant parents and the surrogate parents;

2. Accepting the status of "long-distance parent"/ "substitute parent" and effective educational influences according to this reality;

3. Solving intra-family conflicts and dysfunctional interaction patterns;

4. Increasing parental skills (also taking into account re-adapting to family reunification).

The psychotherapeutic objectives of the intervention on the school group were:

1. developing the capacity for self-knowledge and interconnection;

2. identifying and deciphering one's own and others' emotions;

3. developing self-confidence;

4. developing a sense of belonging, trust and mutual support in the small school group;

5. developing communication and cooperation capacities for pupils in the small school group;

6. achieving group cohesion.

\section{Research Methods}

The design of the present research, being of the qualitativeapplicative type, required the use of the specific methods: the case study, the semi-structured interview, the systematic observation, projective tests with provocative role, experiential techniques with diagnostic value.

The members of three families with structural changes participated in the implemented program of psychoeducational intervention, as well as the teachers and the educational groups to which the children from the respective families belonged. The family dynamics, the type of family relationships, the symptomatology of the children from the three families were similar. In each case, members of the extended family (grandparents) came to the psychological counseling office to improve the emotional and behavioral problems of the grandchildren they were caring for after their parents left to work in other European countries. The age of the children participating in the study ranged from eight to ten years, two being in the third grade and one in the fourth grade. 
The anamnesis performed in each case observed the following areas: the nature and severity of the current problem (frequency, situation in which it occurs, factors that cause or temper it), the presence of other problems and current accusations, current level of development, family structure, family dynamics, intra-family relationships, interpersonal relationships within the school group and among friends. Following the anamnesis and the experiential diagnosis, the following symptomatology was found in children: intense states of anxiety, sadness, low tolerance to frustration, bouts of anger, somatization (gastric pain, nausea, headache), eating and sleeping problems, negative thoughts of persecution, oppositional behaviors towards significant adults, aggressive behaviors towards or isolation from colleagues in the school group. The psychoeducational intervention program was proposed by the psychological counselor following the assessment of the problematic situation in which the families were, the symptomatology and the significance of these symptoms in the context of each family's life scenario.

The theoretical premises at the basis of elaborating the psychoeducational intervention program were:

- Attachment theory;

- The theory of ambiguous loss;

- Theories on assisted resilience;

- Theories on the needs of the child (in the ontogenetic development);

- Theories on the impact of traumatic experiences on child development;

- Studies on the psychological consequences of parental migration on children left in the country;

- Studies on valid therapeutic interventions in assisting the family with structural changes.

The psychoeducational approach undertaken included both individual and group work sessions. It took place over a period of six months, the working sessions being planned in accordance with the therapeutic objectives that were developed throughout, depending on the specificities of each case. Thus, the psychoeducational intervention program included working sessions with the child, with the extended family in whose care the child had remained, with the migrant parents (through online communication), with the teacher and the educational group of which the child was a member.

The methodological stages of the psychoeducational intervention were materialized as follows: 
- The evaluation of the therapeutic context, establishing the "client/ subject" of the intervention and the therapeutic relationship. It was the most important stage of the proposed psychoeducational approach because the correct approach to the emotional and behavioral problems of the child refers to the involvement of all the significant adults who participate in their growth, development and education. In this respect, the "subject" is not only the child, but also the parents, the people in the extended family who take care of them, the teacher, as well as the educational group in which they are included;

- Evaluation of the emotional, cognitive, somatic, behavioral, interpersonal relationship levels (nuclear family, extended family, school group);

- Establishing and implementing the psychoeducational strategy (goals, process and therapeutic techniques);

- The catamnesis - performed six months after the completion of the intervention program.

The psychoeducational intervention program aimed to achieve the objectives presented above and it was structured on the following basic themes: self-awareness and interconnection, increasing resilience, exploring the personal universe, identifying, expressing and managing emotions, selfconfidence, belonging and support, developing parenting skills, assuming educational influences from the perspective of a "long-distance parent" (for migrant parents)/ "surrogate parent" (for grandparents), self-regulation of emotions and self-knowledge of migrant parents and surrogate parents, effective conflict resolution.

Techniques specific to expressive-creative therapies were used in the program: drawing, modelling and collage therapy, drama therapy, experiential metaphor, dance/ movement therapy, therapeutic storytelling, improvisation, affective and relational awareness techniques, awareness development techniques with imaginative support and cognitive restructuring.

\section{Findings}

The integrative psychoeducational intervention, concerned with redressing the family dysfunctionality by re-assigning meaning to the selforiented and interpersonal relationships of its members and their efficient, nourishing adaptation to the reality of the existential plane, led to:

- improvement of the symptomatology of the child's emotional / behavioral disorder; 
- regulation of family relationships;

- increasing the resilience of both children and migrant parents;

- school integration of the child with migrant parents and redefining the relationship with other colleagues.

Furthermore, the fact that all the children in the educational group participated in the program had a positive effect on their personal development. The creative-expressive experiential techniques used during the work sessions contributed to the behavioral development and optimization not only of the child with both migrant parents, but also of the other children in the educational group. Thus, within the experiential group, children were able to express themselves freely and creatively in a secure and inclusive environment, they became aware of their bodily sensations in relation to their own emotions, they managed to identify the emotional states of their playmates, they developed their cooperation, thus increasing the cohesion of the group, they relieved their tension, anxiety was reduced and resistance to frustration was increased, functionally, within the relationship.

The integration of each child in the therapeutic games provided everyone with the opportunity of expressing themselves in their own way, of becoming more confident in themselves and in others, of feeling accepted, valued and loved. Especially since, under one form or another, many of the children's families are affected by different types of structure changes or by the insufficient presence of a family climate.

The program proved to be useful in building beliefs about self, world and life, in discovering new resources, in developing relationships with others based on trust and authenticity.

Moreover, the teachers observed the usefulness of implementing such programs for training and developing resilience and they had the opportunity to experience how expressive-creative techniques are applied, noting that the latter are not limited to this aspect, but they can have a personalized application and on other topics of personal development as well. Thus, they have come to the conclusion that the sanogenous integration of negative life experiences, the identification and development of personal resources capable of coping with adversity can be objectives for the "personal development" curricular area.

\section{Discussions}

Given the fact that the Romanian family is increasingly exposed to the pressure of this reality, of changing its basic structure through the 
phenomenon of migration, the community and the school must pay more attention to the problems that arise in this situation. The child suffers the biggest loss when Romanian society fails to display maturity and to respect one of their fundamental rights, that of growing up and developing near their parents. Migration is seen by families as a way out of the crisis, but without being able to measure the emotional costs by the onset of another crisis, at the level of the human resources of the family as a whole. At present, the educational resources allocated for such situations are limited. Psychoeducational intervention programs are not yet integrated as a must when such a situation occurs.

The fact that, after the period of catamnesis, the results of the psychoeducational intervention were proved to have endured shows that the negative effects of children's separation from their parents - who leave to find work in another country - can be diminished by approaching the problem of these families in this manner, i.e. involving its resources and treating it individually, interdisciplinarily, from several perspectives, reassigning meaning and, thus, paying attention to all existing relationships.

Therefore, the applicative implications of this qualitative research refer to the possibility of carrying out other studies starting from the results of the psychoeducational intervention program implemented, adapting its objectives and structure to other problematic situations that appear in the family and school environment and to offering a different work perspective on the emotional and behavioral disorders of children with migrant parents. It can also be an information resource for education specialists, offering a possible methodological landmark for implementing a personal development approach, as well as for developing a practical psychoeducational guide to prevent the occurrence of such disorders in children. The latter could be useful to both family and educators. Parents could learn how to prepare for their departure from other points of view as well and, above all, how to provide the anchors needed for the sanogenous integration of the temporary separation by the entire family, while educators could view the development of their students' personality from another perspective.

The limits of the research refer to the fact that, since the design is of the qualitative type, the results cannot be generalized. Moreover, the difficulties related to the elaboration and implementation of such intervention programs in the school could be a limitation in regard to the applicative directions of this research. The large number of children in the educational groups, the organizational challenges, the time factor, the insufficient training of the teachers in the field of personal development, the oversized school population "assigned" to a school psychologist can create obstacles in the implementation of this type of intervention program. 
In the case of the present research, it was an advantage that each member of the team actively engaged, with openness, dedication and curiosity in carrying out the intervention program. It can be assumed that, in other situations, the same favorable factors will exist, but this cannot be a certainty. Supporting this idea, Constantin V. emphasizes that the efficiency of a personal development program depends on several factors, among which the individual or group particularities (in the case of group personal development) of the participants, their number, the trainer's style or the motivation of the participants. [6].

\section{Conclusions}

The effects of migration and implicitly of the change in the family structure are experienced subjectively by each family and, as such, in this situation, the individualization of the therapeutic intervention is a necessity. The integration of the family in a psychoeducational intervention program focused on increasing the resilience of its members, developing socioemotional skills, flexibility and autonomy, and on using the educational group as a resource can be a solution to minimize the negative effects on the psychological development of the children, effects which might arise in this context of temporary separation.

Because the consequences of changing the family structure by the departure of the parents abroad affect the whole family system from an emotional, cognitive, interpersonal point of view, the therapeutic intervention on the child with emotional and/ or behavioral disorders who is part of a family with migrant parents cannot be addressed in isolation from family and school. Thus, as far as possible, relations with the significant people who remain by them and contribute to their development, support and education should be taken into account. Furthermore, the emotional and behavioral symptoms should be seen as compensatory reactions of the child in this situation which for them is traumatic.

The implementation of psychoeducational intervention programs (both for preventive and remedial purposes) through multidisciplinary teams, at national level, by and in the authorized institutions, on the basis of scientific theoretical premises and a rigorous methodological framework, could be a solution for the recovery and redefinition of the resources of the Romanian family, increasingly challenged by the phenomenon of migration 


\section{References}

[1] Badea M. O perspectiva psihologica asupra experientelor de separare din viata. Bucuresti: SPER; 2019. 565 p.

[2] Botezat A, Pfeiffer F. The Impact of Parents Migration on the Well-Being of Children Left Behind-Initial Evidence from Romania. IZA Discussion Paper. 2014, 05; 82(25): 14-029.

[3] Boza M. Parentingul la distanta: parinti divortati, imigranti sau absenti. In: Pânisoară G, Sălăvăstru D, Mitrofan L. (coord.). Copilaria si adolescenta: provocări actuale în psihologia educatiei si dezvoltării, Iasi: Polirom; 2016. 22 p.

[4] Cojocaru M, Gulei A, Irimescu G, Luca C, Lupu A, Miftode DV. Migrația şi efectele ei în plan familial. OIM; 2006. Available from: http://singuracasa.ro/_images/img_asistenta_sociala/pentru_profesionisti/re surse_asistenta_sociala_copil_singur_acasa/abilitati/Migratia_si_efectele_ei_in _plan_familial_OIM2006.pdf

[5] Comunian AL. Rezilienta si familie. JEP. 2009 june; 2(46):3-7.

[6] Constantin V. Poveste, metafora, dezvoltare personala - improvizatia creatoare prin literatură. Bucuresti: SPER; 2016. 207 p.

[7] Ionescu S. Domeniul rezilientei asistate. In: Ionescu S (coord). Tratat de rezilienta asistata. Bucuresti: Trei; 2013.29 p.

[8] Marc G. Abuzul la copii: diagnoza si interventie terapeutica. Bucuresti: SPER; 2015. 258 p.

[9] Mitrofan N. Promovarearezilientei la copii. JEP. 2002 jun; 18-19:1-4.

[10] Muntean A. Psihologia dezvoltării umane. Iasi: Polirom; 2006. 432 p.

[11] Toth G. O abordare calitativă asupra riscurilor la care sunt expusi copiii cu părinti plecati la munca în străinătate. In: Toth $G$, Toth $A$, Voicu $O$, Stefănescu M (coord.). Efectele migratiei: copiii rămasi acasă. Bucuresti: Fundatia Soros România; 2007. pp. 4-13.

[12] Yanovich L. Children left behind: the impact of labor migration in Moldova and Ukraine. $2015 . \quad$ AIS; from: https://www.migrationpolicy.org/article/children-left-behind-impact-labormigration-moldova-and-ukraine. 